\title{
Prueba indiciaria en la jurisprudencia peruana y su relación con el razo- namiento presuntivo: inducción, deducción y abducción
}

In the peruvian circunstancial evidence jurisprudence and its relationship with presumptive reasoning: induction, deduction and abduction

\author{
Elmer Robles Blacido ${ }^{1}$, Félix Julca Guerrero ${ }^{1}$, Luis Robles Trejo ${ }^{1}$, \\ Víctor Flores Leiva ${ }^{1}$ y Laura Nivin Vargas ${ }^{1}$
}

\section{RESUMEN}

Desarrolla la prueba indiciaria relacionada al razonamiento presuntivo. El estudio tuvo como fuente de análisis el razonamiento que realizan magistrados cuando aplican la prueba indiciaria en la resolución de casos. Para ello se recurrió a la jurisprudencia más saltante, de donde se extrajo los datos empíricos necesarios e ilustrativos que conllevaron a determinar la triple manifestación o posibilidad de realización: inducción, deducción y abducción. Según la jurisprudencia y la doctrina se usa o sustenta indistintamente el razonamiento presuntivo en la inducción, la deducción y la abducción y, por consiguiente, es visible la falta de coherencia y racionalidad plena principalmente en las decisiones judiciales.

Palabras clave: prueba indiciaria; proceso penal; razonamiento presuntivo; inducción; deducción y abducción.

\begin{abstract}
This research develops circumstantial evidence related to the presumptive reasoning. The study was a source of analysis the reasoning that perform judges when applying circumstantial evidence in resolving cases. It relied for the most striking case, where the empirical data needed and illustrative that led to determine the triple manifestation or extracted possibility of realization: induction, deduction and abduction. According to case law and doctrine used interchangeably or presumptive reasoning based on induction, deduction and abduction and therefore is visible lack of coherence and rationality mainly full judicial decisions.
\end{abstract}

1 Universidad Nacional «Santiago Antúnez de Mayolo». Huaraz, Perú. 
Keywords: circumstantial evidence; criminal proceedings; presumptive reasoning; induction; deduction and abduction.

\section{ICHIKLLACHAW}

Kay qillqaqa imanaw prueba indiciaria kaqantam willakun. Tsayta allimpa kaayinapaq ñawikashqa washaakuq magistradukunapa hatun yuyayninkunatam, pueba indiciariata churayaptin ashanakuyta, maqanakuyta allinman kutitsiyaananpaq. Tsaypaqmi jurisprudencia nishqanta ñawiqashqa, tsaypita kimsantin allin kaq willakuykunata hurqakashqa: indiccion, deducción, niykur abdicacion. Jurisprudenciawan doctrina tukuy laayapam wanayan, kaayiyan hatun yuyayta induccionchaw, deduccionchaw, niykur adbicacionchaw. Tsayraykurmi rikantsik, kaayintsik kay ruraykunaqa manam tsaynallatsu kaayikaayan, sinuqa tukuy laayapam.

Pushaq shimikuna: pueba incidiaria, llakikuy proceso, presuntivo yuyay, inducción, deducción, niykur abdicación.

\section{INTRODUCCIÓN}

El uso de la prueba por indicios o prueba indiciaria se constituye como una práctica usual en la administración de justicia penal peruana a falta de la prueba directa. De la práctica diaria que realizan los abogados como operadores del derecho, se advierte que las instancias jurisdiccionales penales de todo nivel, tienen variados criterios respecto al razonamiento probatorio o más exactamente del razonamiento presuntivo.

En la literatura especializada se refiere que, sin prueba no hay verdad, menos proceso. El proceso se justifica porque pretende probar no en abstracto, sino en concreto la existencia o no de un hecho criminoso. Para ello permite la participación de los sujetos procesales en igualdad de condiciones. Pero el proceso y la verdad, tienen su justificación en el afán cognoscitivista del hombre. Al respecto, Ferrajoli (2001) señala que, a diferencia de cualquier otra actividad jurídica, la jurisdiccional, en el estado de derecho, es una actividad no sólo práctica o prescriptiva, sino también teorética. Incluso, es una actividad prescriptiva que tiene por necesaria justificación una motivación total o parcialmente cognoscitiva. Es más, la prueba permite que el derecho se haga real, más objetivo y más accesible. En rigor, la prueba es un aspecto fundamental del derecho porque es su conexión con la realidad. El derecho sin pruebas no sería sino una suerte de matemática abstracta o un relato de ficción. La prueba hace terrenal al derecho, lo hace partícipe del mundo de los hombres. Pero lo hace también justo; porque un derecho perfectamente coherente e ideal pero aplicado a tientas o sin correlación con la realidad, sería inicuo (De Traszgnies, s/f.).

El proceso judicial busca la verdad, pero esta búsqueda no siempre es absoluta, menos puede convertirse en el fin que justifica los medios. El proceso judicial busca la verdad por medio de la prueba. Ésta persigue tener un conocimiento completo de las cosas so- 
bre las cuales deberá aplicarse una norma jurídica. Pero, como el absoluto es imposible para el hombre, lo probado será siempre un mero acercamiento a la verdad sin llegar nunca al conocimiento total del hecho (Ibid.).

En este marco, se entiende que los tribunales de todo nivel aplican -o por lo menos refieren- que aplican la prueba por indicios. Precisamente, partiendo de esa realidad, con esta investigación se propuso determinar qué tipo de razonamiento presuntivo aplican los tribunales cuando refieren resolver el caso recurriendo a la prueba por indicios.

A continuación, se presenta ese razonamiento o tipo de razonamiento que realizan los magistrados, cuando refieren la explicación de la prueba indiciaria. Los resultados de este estudio han de servir para reflexionar mejor, profundizar en la misma, y lógico, encontrar sus incoherencias que deben ser superadas, con la finalidad de ser racionales en nuestras decisiones que son consecuencias de nuestros razonamientos.

\section{MATERIALES Y MÉTODOS}

Se trata de un estudio no experimental, retrospectivo-descriptivo y explicativo. Su abordaje se desarrolla desde una perspectiva cualitativa centrada en la descripción y análisis detallada que bordea lo ético para ingresar a lo émico de la realidad estudiada que es un hecho jurídico actual y característico de la administración de justicia penal.

Los métodos usados en el trabajo fueron: la argumentación jurídica para la confrontación de las teorías jurídicas y la demostración lógica de las incoherencias de algunas decisiones; el método hermenéutico para la interpretación de las decisiones judiciales con el objetivo de encontrar su verdadero significado a partir de la doctrina jurídica existente. Asimismo, se emplearon los métodos generales de inducción y deducción, los mismos que han sido referidos, sustentados y cuestionados a partir de casos concretos.

Las técnicas usadas fueron el análisis documental y el registro documental. La primera con la finalidad de auscultar la jurisprudencia de los tribunales ordinarios del ámbito penal, así como del Tribunal Constitucional y; la segunda, para contar con información respecto a la doctrina a confrontar con la realidad jurídica concreta. Como instrumentos se utilizó la ficha de análisis documental y la ficha de registro documental.

\section{RESULTADOS}

\section{La prueba indiciaria}

1.1. Prueba directa e indirecta en el proceso penal. La prueba busca la verdad, persigue tener un conocimiento completo de las cosas sobre las cuales deberá aplicarse una norma jurídica. Existen pruebas directas e indirectas en el proceso judicial. A pesar que aparentemente, no existe discrepancia entre ambas pruebas, un análisis profundo nos conlleva necesariamente a problematizar tal aparente e ingenua 'verdad'. 
En la siguiente historia hipotética sobre una investigación penal por el delito de lesiones se tiene que $\mathbf{X}$ lesionó a $\mathbf{Y}$, según ha referido la testimonial de $\mathbf{Z}$. Esta afirmación requiere las siguientes advertencias antes de aceptarla per se como cierta e irrefutable: ¿No existe duda sobre la credibilidad de Z Z? ¿Z no sufrirá algún error en la percepción?, ¿No existirá algún error de interpretación de los hechos de Z Z? ¿...?

De la historia presentada, podemos deducir que ¿la testimonial de $\mathbf{Z}$ es una prueba directa? Según la doctrina, sí lo es. Sin embargo, para establecer la responsabilidad penal de $\mathbf{X}$ requerimos realizar un conjunto de razonamientos. Entonces, ¿ello no lo convierte en prueba indirecta?

Como se advierte, a partir de un hecho hipotético o real, existe una compleja y difícil diferenciación entre la prueba directa e indirecta. Al respecto, Miranda (1997: 218) asume que tomando como punto de partida la estructura jurídica de la prueba procesal, la prueba directa se obtienen afirmaciones instrumentales que, previa su depuración, son susceptibles de ser comparadas directamente con las vertidas en los escritos de conclusiones definitivas; mientras que en la prueba indirecta las afirmaciones instrumentales, depuradas, que se obtienen permiten a su vez extraer nuevas afirmaciones que son las que se utilizarán como término de comparación con las que se realizaron en los mencionados escritos de acusación y defensa.

La diferenciación establecida por Miranda (Ibíd.) tampoco es irrefutable, pues la diferencia entre prueba directa e indirecta no solo es difícil, sino también sus fronteras casi son imperceptibles. Al respecto, Gonzales (2005: 94) sostiene que «la distinción entre prueba directa e indirecta es una cuestión de grado, que dependerá del número de inferencias que haya que realizar y del carácter más o menos evidente de las máximas de la experiencia. Por ello, no habiendo diferencia cualitativa entre ambos tipos de prueba, se puede afirmar que los criterios de solidez rigen tanto para la prueba directa como para la indirecta». En adición, Bovino (2005: 6) señala que, en el marco del sistema de la sana crítica, todos y cada uno de los medios y elementos probatorios son, en realidad, indicios. En muy pocas ocasiones un elemento de prueba, considerado aisladamente, tiene la capacidad de demostrar directa y fehacientemente los distintos elementos fácticos que componen el objeto procesal.

En suma, a partir de estas premisas, se puede inferir que si bien de manera general es posible diferenciar la prueba directa de la indirecta; sin embargo, en el caso concreto y específico, ésta diferenciación es casi inexistente o imperceptible o, en su defecto, muy difícil de establecer.

1.2. Constitucionalidad de la prueba indiciaria. Se parte formulando dos preguntas de rigor: ¿es constitucional la prueba indiciaria?, ¿no trastoca ningún derecho fundamental? La pertinencia de estas preguntas, se basa en que la Lex superior, en un Estado de Derecho, se constituye en el marco normativo esencial que tiene el derecho penal y el derecho procesal penal. Con el proceso penal, lo que se pretende es defender los derechos fundamentales de las partes, pudiendo ser del inculpado o víctima.

Según, el Tribunal Constitucional (TC), el deber de protección de los derechos funda- 
mentales vincula inmediata y directamente a los jueces, durante el desarrollo de un proceso penal; lo cual, sin embargo no puede significar la omisión de tutelar otros bienes o valores jurídicos constitucionalmente valiosos. Por ende, el respeto de los derechos de los procesados no es incompatible con el deber de los jueces de determinar la responsabilidad penal del procesado (STC Exp. N 9081-2006-HC/TC, F.J. 16). Además, el derecho fundamental a la prueba tiene protección constitucional, en la medida en que se trata de un contenido implícito del derecho al debido proceso, reconocido en el artículo 139, inciso 3, de la Constitución. En este sentido, una de las garantías que asiste a las partes del proceso es la de presentar los medios probatorios necesarios que posibiliten crear convicción en el juzgador sobre la veracidad de sus argumentos. Sin embargo, como todo derecho fundamental, el derecho a la prueba también está sujeto a restricciones o limitaciones, derivadas tanto de la necesidad de que sean armonizados con otros derechos o bienes constitucionales -límites extrínsecos-, como de la propia naturaleza del derecho en cuestión -límites intrínsecos- (STC Exp. Nº431-2005-HC/ TC, F.J. 4-9).

En ese sentido, el Supremo intérprete de la Constitución ha precisado que la prueba capaz de producir un conocimiento cierto o probable en la conciencia del juez debe reunir las siguientes características: veracidad objetiva, constitucionalidad de la actividad probatoria, utilidad de la prueba y pertinencia de la prueba (STC Exp. 1014-2007$\mathrm{PHC} / \mathrm{TC}, \mathrm{F} . J .12)$.

Siguiendo la misma lógica, el TC justificando la constitucionalidad de la prueba indiciaria ha precisado que: «...si bien el juez penal es libre para obtener su convencimiento porque no está vinculado a reglas legales de la prueba y, entonces, puede también llegar a la convicción de la existencia del hecho delictivo y la participación del imputado, a través de la prueba indirecta (prueba indiciaria o prueba por indicios)» (STC Exp. 0728-2008-PHC/TC, F.J. 25).

Por su parte, la Corte Americana de Derechos Humanos, en una de sus sentencias señaló que «en ejercicio de su función jurisdiccional, tratándose de la obtención y la valoración de las pruebas necesarias para la decisión de los casos que conoce puede, en determinadas circunstancias, utilizar tanto las pruebas circunstanciales como los indicios o las presunciones como base de sus pronunciamientos, cuando de aquéllas puedan inferirse conclusiones consistentes sobre los hechos» (SCIDH, 1998, Blake versus Guatemala, F.J. 47). Además, señala que la prueba indiciaria o presuntiva resulta de especial importancia cuando se trata de denuncias sobre la desaparición, ya que esta forma de represión se caracteriza por procurar la supresión de todo elemento que permita comprobar el secuestro, el paradero y la suerte de las víctimas (Ibíd:: 49).

Por su parte, la Corte Suprema del Perú, ha argumentado que «en este delito adquieren gran importancia las pruebas testimoniales, como los indicios, la prueba circunstancial y las presunciones, en tanto, esta forma de represión se caracteriza por procurar la supresión de todo elemento que permita comprobar la desaparición y la suerte de la víctima» (Ejecutoria Suprema, Exp. 2779-2006). 
1.3. Derecho a la verdad como fundamento constitucional de la prueba indiciaria. El TC ha sustentado que el derecho a la verdad es la posibilidad de conocer las circunstancias de tiempo, modo y lugar en las cuales ellos ocurrieron, así como los motivos que impulsaron a sus autores. Éste es el derecho a la verdad en su dimensión colectiva. En contraste, en su dimensión individual, el derecho a la verdad permite el conocimiento de las circunstancias en que se cometieron los hechos con contenido penal. Las personas, directa o indirectamente afectadas por un crimen de esa magnitud, tienen derecho a saber siempre, aunque haya transcurrido mucho tiempo desde la fecha en la cual se cometió el ilícito, quién fue su autor, en qué fecha y lugar se perpetró, cómo se produjo, por qué se le ejecutó, dónde se hallan sus restos, entre otras cosas (STC Exp. $\mathrm{N}^{\circ}$ 2488-2022-HC/TC, F.J. 8-9). Entonces, ante la ausencia de la prueba directa, deviene en necesaria y obligatoria la prueba por indicios, más aún si se tiene en cuenta que el derecho a la verdad se constituye en un derecho fundamental.

\section{Referencias en la doctrina y la jurisprudencia sobre el razonamiento presuntivo}

2.1. Doctrina nacional. No hay mucha literatura especializada en materia de prueba indiciaria; sin embargo, hay algunas que han llenado vacíos y han planteado algunas respuestas a tantas interrogantes sobre la prueba indiciaria, especialmente en lo referido al razonamiento probatorio o presuntivo en este tema.

Mixan Mass (2003) señala que la inferencia inductiva comprende ocho subclases: por enumeración completa, por coligación, por inducción matemática, por reconstrucción, por recurrencia, por inducción amplificadora (inducción incompleta), por muestreo, inducción estadística, concordancia, discordancia (diferencia), por residuo y por variaciones concomitantes. No obstante, el autor no es explícito respecto al razonamiento probatorio. Por su parte, García (2016: 66) sostiene que la prueba del indicio, por sí mismo, no prueba directamente el hecho penalmente relevante, por lo que el aporte probatorio respecto del objeto del proceso se da propiamente con el razonamiento deductivo. Este razonamiento deductivo debe estar respaldado en una ley científica, una regla de la lógica o una máxima de la experiencia como reglas del criterio humano. Como se puede observar, para García el razonamiento deductivo en la prueba indiciaria juega un papel primordial, pues no hay ninguna referencia a otro tipo de razonamientos como el inductivo y abductivo.

Concordante con esta postura, el Rosas (2004) señala que entre los indicios y la conclusión debiera existir una correlación que descarte toda irracionalidad en el proceso deductivo. En otras palabras, el juicio de inferencia no sea arbitrario o absurdo, sino que sea coherente y se ajuste a las normas del criterio humano; debiendo ser explicado en la sentencia ese proceso lógico de deducción realizado, para de esta manera cumplir con las exigencias de motivación derivadas del artículo $139.5^{\circ}$ de la Constitución. Como se puede observar, para Rosas, el proceso lógico importante en la prueba indiciaria es el razonamiento deductivo, no hay ninguna otra referencia más, de lo que podemos concluir que solo éste es aplicable al tema que nos ocupa. 
El Art. 158.3, inciso b) exige que la inferencia esté basada en las reglas de la lógica, la ciencia o la experiencia (común). Al respecto, Talavera (2009:139) señala que: «La inferencia consiste en la deducción que se hace, basada en las reglas de la experiencia o en el conocimiento de determinadas cuestiones técnicas o científicas, del hecho conocido para inferir la existencia o inexistencia de otro, que es su consecuencia». También se puede advertir una postura genérica y hasta escéptica como la de Ramos (2009: 109) cuando asevera que «para ser valorado con eficacia probatoria, como prueba indirecta o indiciaria, se requiere que el indicio, tras una inferencia lógica, nos conduzca ante el reconocimiento de dos hechos, uno comprobado (dato objetivo) y el otro no manifestado aún (dato por conocer), que se trata de demostrar mediante el razonamiento lógico, pudiéndose clasificar en indicios anteriores, concomitantes y posteriores al hecho delictivo objeto de la investigación, relacionados con el objeto de prueba».

2.2. Jurisprudencia nacional: Prueba indiciaria, una confusión entre inducción, deducción y abducción

A continuación se presenta como evidencia empírica algunos extractos de las sentencias emitidas en nuestro país.

(1) «Lo referido precedentemente se corrobora con los indicios de mala justificación brindados por el encausado (¿’?), quien en el afán de evadir su responsabilidad incurrió en serias contradicciones, así, en su manifestación policial... inicialmente refirió no tener teléfono celular, no obstante al preguntársele sobre el celular hallado en su poder al momento de su intervención y en el cual estaban registrados números y llamadas entrantes y salientes a los celulares de los demás encausados, refirió que efectivamente dicho teléfono le pertenecía y fue un regalo de su esposa, quien se encontró dicho teléfono cuando viajaba en un trimovil» (E.S. Exp. N²913-3739).

Como se puede observar, no se hace referencia a ningún tipo de razonamiento, solo se menciona a una clasificación de los indicios.

(2) «Que, respecto al indicio, (a) este -hecho base- ha de estar plenamente probado por los diversos medios de prueba que autoriza la ley- pues de lo contrario sería una mera sospecha sin sustento real alguno, (b) deben ser plurales, o excepcionalmente únicos pero de una singular fuerza acreditativa, (c) también concomitantes al hecho que se trata de probar - los indicios deben ser periféricos respecto al dato fáctico a probar, y desde luego no todos lo son, y (d) deben estar interrelacionados, cuando sean varios, de modo que se refuercen entre sí y que no excluyan el hecho consecuencia no sólo se trata de suministrar indicios, sino que estén imbricados entre sí- (...); que, en lo atinente a la inducción o inferencia, es necesario que sea razonable, esto es, que responda plenamente a las reglas de la lógica y la experiencia, de suerte que de los indicios surja el hecho consecuencia y que entre ambos exista un enlace preciso y directo» (E.S. Exp. 1912-2005).

En este caso, la sentencia menciona una confusión «inducción o inferencia» (confundiendo el todo con la parte). Asimismo, señala que el único razonamiento en la prueba indiciaria es el inductivo. 
(3) «...Que la prueba por indicios requiere, como es sabido, (i) que los indicios -su objeto no es el directamente final de la prueba: la conducta delictiva- se basen en hechos plenamente probados y no en meras sospechas, rumores o conjeturas; y, (ii) que los hechos constitutivos de delito y la participación de los acusados en el mismo, se deduzcan de los indicios a través de un proceso mental razonado y acorde con las reglas del criterio humano, detallado en la sentencia condenatoria. El control impugnativo de la racionalidad y solidez de la inferencia puede efectuarse tanto (i) desde el canon de su lógica o coherencia -de modo que será irrazonable si los indicios acreditados descartan el hecho de que se hace desprender de ellos o no conduzcan naturalmente a él-, como (ii) desde el de su suficiencia o carácter concluyente -no siendo razonable cuando la inferencia es excesivamente abierta, débil o imprecisa-. ...» (E.S. Exp. N²012-3521).

Del extracto de la sentencia, se advierte que para llegar a lo desconocido a partir de lo conocido, solo es aplicable el razonamiento deductivo.

(4) «... existe una concurrencia de indicios que permiten concluir que el autor del ilícito investigado es el acusado XX entre [...] [tales indicios] cabe destacar los siguientes: a) Indicio de móvil: ...; b) Indicio de oportunidad: ...; c) Indicio de mala justificación....; y d) Indicio de actitud sospechosa: ...» (E.S. Exp. N 1787-98).

Los criterios a que alude la Corte Suprema respecto de la prueba indiciaria, son los que presenta Gorphe (2007: 222), sin mayor explicación del razonamiento que realizan.

(5) «Presunción o enlace de razonamiento deductivo. Es lo que permite vincular los dos hechos, estableciendo entre ellos la relación de causalidad. Esta relación de causalidad se construye - por exigencia del art. 158.3.b) del CPP de 2004- a partir de las reglas de la lógica, las máximas de la experiencia o los conocimientos científicos, esto es, juicios generales que van más allá del caso concreto y que, por tanto, constituyen criterios de predicción causal. Respecto al proceso deductivo, se requiere que la relación entre el indicio y el resultado sea directa, o sea que el enlace entre ambos elementos sea preciso y directo» (Resolución de Vista, Exp. N²008-295-81).

En este caso, una vez más se asevera con una verdad irrefutable el razonamiento deductivo como el único aplicable en la prueba indiciaria.

\section{DISCUSIÓN}

\section{Puede ser inducción el razonamiento presuntivo que señalan nuestros magistrados}

Caso hipotético: «El padre y la madre de la familia Pacheco Machado (cuyos hijos son 6), están condenados por el delito de tráfico ilícito de drogas. Juan, el mayor de los hermanos también, el tercero acaba de ser capturado por posesión ilícita de drogas. En consecuencia, todos los integrantes de la familia Pacheco Machado son traficantes de drogas». ¿De este hecho hipotético se puede derivar la responsabilidad penal de toda la familia?, ¿No hay la posibilidad de que alguno de los hermanos sean ajenos o por lo menos, por ahora, contrario a lo que realiza su familia? 
López y otros (2011: 35) sostienen que «en materia de prueba indiciaria, debe operar la inducción, en la que subyacen argumentos a partir de una serie de casos y resultados y de los cuales extraemos máximas o reglas que correlacionan el indicio con el hecho indicado. En los argumentos inductivos, extraemos una premisa de carácter general a partir del examen de una serie limitada de supuestos particulares, de manera que la conclusión siempre va más allá de las premisas. En una inducción siempre hay un «salto» de las premisas a la conclusión, por lo que la verdad de unas no nos garantiza la verdad de la otra». Ello significa que de un hecho conocido a otro desconocido, se llega mediante la inducción. Sin embargo, del ejemplo hipotético y de los argumentos doctrinales presentados, se tiene que no necesariamente es así. En todo caso hay un equívoco.

Coherente con lo mencionado, De Miranda (2014: 211-212) señala que: «La inducción cuantitativa no permite en absoluto inferir un hecho a partir de otro conocido o probado. Si alguna utilidad se le encuentra en relación con la inferencia presuntiva es que, merced a aquel tipo de inferencia, se construyen máximas de experiencia».

De los abstractos de las sentencias judiciales antes referidas se advierte que se confunde el razonamiento presuntivo como razonamiento inductivo (en especial, Acuerdo Plenario N. $\left.{ }^{\circ} 1-2006\right)$. Creemos que es erróneo lo siguiente: «...., en lo atinente a la inducción o inferencia, es necesario que sea razonable, esto es, que responda plenamente a las reglas de la lógica y la experiencia, de suerte que de los indicios surja el hecho consecuencia y que entre ambos exista un enlace preciso y directo» ( Acuerdo Plenario N. ${ }^{\circ}$ 1-2006). Primero, porque el razonamiento inductivo permite la construcción máxima de la experiencia y no que responda a la máxima de la experiencia. Segundo, porque a partir de un hecho particular no se puede generalizar y con ello imputar responsabilidad penal.

\section{Puede ser la deducción el razonamiento presuntivo que señalan muestros magistrados}

«A testifica que ha visto a B salir muy presuroso y temeroso de la casa de $\mathrm{C}$ con un cuchillo ensangrentado en la mano, poco antes de que este fuese hallado muerto de una cuchillada (hecho base). De acuerdo a la máxima de la experiencia, quien sale de una casa en estas condiciones, es decir, muy presuroso y temeroso, y con un cuchillo ensangrentado en la mano es porque ha matado a una persona (razonamiento deductivo). $\mathrm{Al}$ haber sido hallado muerto $\mathrm{C}$ producto de una cuchillada, podemos inferir que $\mathrm{B}$ ha matado a $\mathrm{C}$ (hecho consecuencia). Esto último es consecuencia del hecho base» (STC, Exp. No728-2008-PHC/TC, F.J, N²9).

Al parecer, a partir de esta sentencia del TC, se ha pretendido generalizar el razonamiento deductivo, como única forma cuando se pretende ir a lo desconocido partiendo de lo conocido; por lo tanto, esta sería la única forma de razonamiento válido cuando se trata de prueba indiciaria.

Sin embargo, esta «verdad», tiene su refutación. Por ejemplo, De Miranda (2014: 208209), con mucha pertinencia sostiene que «la deducción es una inferencia en la que se cumple que, de ser materialmente verdaderas las premisas, la conclusión ha de ser materialmente verdadera, de forma necesaria. Y para que eso ocurra, entre otras cosas, 
la regla (máxima de la experiencia) tiene que ser verdadera siempre y en todo caso. Dicho de otra manera, la regla tiene que ser universal y absolutamente válida. O sea que carezca de excepciones».

Analizados los hechos y los pronunciamientos de nuestros magistrados, se tiene que esa posibilidad es irrealizable en los casos donde se aplica el razonamiento deductivo. Así, por ejemplo, en el caso hipotético que presenta el TC en el caso Llamoja (la participación de $\mathrm{A}, \mathrm{B}$ y $\mathrm{C}$ en un caso de supuesto homicidio), se tendría necesaria y obligatoriamente como conclusión de que $\mathrm{B}$ ha matado a $\mathrm{C}$; pero esa conclusión no es absoluta. Puede darse el caso (no descartado) de que A ha confundido los hechos. También puede presentarse la posibilidad de que B encontró el cuchillo ensangrentado y muerto a C; por tanto, en su desesperación, susto y confusión cogió el cuchillo y salió a la calle con la finalidad de dar aviso a alguien, al no observar a nadie se confundió. Es decir, la conclusión no es categórica. Hay circunstancias probables.

En el Expediente N²008-295-81, que se ha transcrito se advierte una confusión doctrinal y hasta conceptual, cuando hace referencia la razonamiento deductivo de la siguiente manera: «Es lo que permite vincular los dos hechos, estableciendo entre ellos la relación de causalidad, esta relación de causalidad se construye -por exigencia del art. 158.3.b) del CPP de 2004- a partir de la reglas de la lógica, las máximas de la experiencia o los conocimientos científicos, esto es, juicios generales que van más allá del caso concreto y que, por tanto, constituyen criterios de predicción causal». Al respecto, es oportuno diferenciar entre prueba por indicios y prueba por presunción, que la resolución en comentario confunde de manera clamorosa. Es necesario recordar: «...Que toda prueba indirecta, sea presunción o indicio, presenta la forma lógica del raciocinio; pero mientras el raciocinio de la presunción va de lo conocido a lo desconocido, con el auxilio del principio de identidad, el raciocinio del indicio, por el contrario, va de lo conocido a lo desconocido, a la luz del principio de causalidad» (Díaz, 2002:10).

\section{Puede ser la abducción el razonamiento presuntivo que señalan nuestros magistrados}

Sobre este asunto, Bonorino (2014: 180) señala que «entender la abducción como un procedimiento en el que se plantean problemas, se tienen en cuenta los datos relevantes disponibles, se formulan conjeturas y se las pone a prueba a partir de la obtención de nuevas evidencias, utilizando en proceso distintos tipos de inferencias, hasta terminar aceptando una de esas hipótesis como la menos falsa o la más verdadera...». En la doctrina nacional, De Trazegnies (s/f.: 1) aboga por la abducción como inferencia presuntiva señalando que «la prueba indiciaria supone un pensamiento complejo en el que se persigue la reconstrucción de un hecho concreto, remontando de ciertos indicios a hechos que se hacen más o menos probables a medida que avanza el proceso de recolección de indicios y de formulación de presunciones o conjeturas basados racionalmente en tales indicios». Asimismo, añade que «el razonamiento que emplea la prueba indiciaria es siempre persuasivo, nunca demostrativo: pretende convencer, no explicar. Una mera explicación de la situación tendría que basarse sobre hechos 
evidentes, libres de toda ambigüedad o duda. En cambio, en los indicios no hay nada seguro salvo el hecho bruto inicial que es interpretado como indicio; porque todo lo demás (incluyendo su carácter de indicio) lo alega quien pretende convencernos de lo sucedido. Por eso, la prueba indiciaria, netamente argumentativa, «nos obliga en efecto a tener en cuenta no solamente la selección de datos, pero también la manera como se los interpreta, la significación que uno escoge darles... [es, pues,] una elección, más o menos consciente, entre varios modos de significación» (Ibid.).

Si confrontamos estas ideas con las muestras materializadas en las sentencias, ninguna hace mención o alusión como forma de razonamiento en la prueba indiciaria a la abducción. Solo se ha llegado a afirmar de dos formas de razonamiento: inductivo y deductivo. Para nuestra jurisprudencia no existe el razonamiento abductivo.

\section{CONCLUSIONES}

La prueba indiciaria es indispensable para averiguar la verdad en el proceso penal; es más, no hay argumento para reclamar su inconstitucionalidad. El razonamiento presuntivo o razonamiento probatorio (en la prueba indiciaria), tiene una triple manifestación o posibilidad de realización: Inducción, deducción y abducción.

La jurisprudencia (de tribunales penales ordinarios y el propio Tribunal Constitucional) sobre prueba indiciaria, sostiene indistintamente a la deducción e inducción como razonamientos para llegar a lo desconocido a partir de lo conocido. Por su parte, la doctrina nacional, tiene claridad y suficiente fundamento para postular el razonamiento inductivo, deductivo o abductivo cuando se trata de usarlo en la prueba indiciaria.

\section{REFERENCIAS BIBLIOGRÁFICAS}

Bonorino, Pablo. 2014. Ni deducción, ni inducción: abducción, en: García Amado, Juan Antonio y Bonorino Pablo Raúl (coords). 2014. Prueba y razonamiento probatorio en Derecho-debates sobre la abducción-. Granada: Comares.

Bovino, Alberto. 2005. La actividad probatoria ante el Corte Interamericana de Derechos Humanos. <http:/ /www.scielo.br/scielo.php?pid=S1806-64452005000200005\&scrip$\mathrm{t}=$ sci_arttext\&tlng=es $>$ [Consulta: 12-12-2015].

García, Percy. 2016. La prueba por indicios en el proceso penal. Lima: Reforma.

De Miranda, Carlos. 2014. Prueba indiciaria: ¿deducción? ¿inducción? ¿abducción? ¿o inferencia a la mejor explicación?. En: García Amado, Juan Antonio y otro (coords.)(2014). Prueba y razonamiento en Derecho -debates sobre abducción-Granada: Comares.

De Traszegnies, Fernando. 2015. La teoría de la prueba indiciaria. < http:/ / macareo.pucp. edu.pe//ftrazeg/aafad.htm> [Consulta 23-10-2015].

Diaz de León, Marco. 2002. «La prueba indiciaria». En Quiceno, F. y otros. Indicios y presunciones. Caracas: Jurídica Bolivariana. 
Ferrajoli, Luigui. 2001. Derecho y razón -teoria y garantismo penal-. Madrid: Trotta S.A.

García, Juan y otro (coords.). 2014. Prueba y razonamiento en Derecho-debates sobre abducción-. Granada: Comares.

Gonzales, Daniel. 2005. Quastio Facti: ensayos sobre prueba, causalidad y acción. Lima: Palestra-Temis.

Gorphe. 2007. Apreciación judicial de la prueba (traducción Alcalá-Zamora y Castillo). Buenos Aires.

López, Reiser y otros. 2011. Manual de litigación en prueba indiciaria. Lima: ARA.

Miranda, Manuel. 1997. La minima actividad probatoria en el proceso penal. Barcelona: José M. Bosh.

Mixan Mass, Florencio. 2003. Indicio - prueba indiciaria-. Trujillo: BLG.

Rosas, Jorge. 2004. Prueba indiciaria: Doctrina y jurisprudencia nacional. Anuario de derecho penal < http://perso.unifr.ch/derechopenal/assets/files/anuario/ an_2004_14.pdf> [Consulta: 24-10-2015].

Pabón, German. 1995. Lógica del indicio en materia criminal. Bogotá: Themis.

Pastor, Francisco. 2003. Prueba de indicios, credibilidad del acusado y presunción de inocencia. Valencia: Tirant lo Blanch.

Quiceno, Fernando (comp.). 2002. Indicios y presunciones. Caracas: Jurídica Bolivariana.

Ramos, Carlos. 2009. El razonamiento fiscal de la sospecha al indicio. Lima: Magna.

Talavera, Pablo. 2009. La prueba en el nuevo proceso penal-Manual del derecho probatorio y de la valoración de las pruebas. Lima: Academia de la Magistratura.

Fecha de recepción: 22 de febrero 2016

Fecha de aceptación: 27 de mayo 2016

\section{Correspondencia}

Elmer Robles Blacido

elmer_rb_30@hotmail.com 